Ç.Ü. Sosyal Bilimler Enstitüsü Dergisi, Cilt 28, Sayı 2, 2019, Sayfa 272-285

\title{
KÜRESEL ÖLÇEKTE ENERJİ SEKTÖRÜNÜN REKABET GÜCÜNÜN DEĞERLENDİRILMESİ: MINT ÜLKELERİ ÖRNEĞİ
}

\author{
Betül ALTAY TOPCU ${ }^{1}$
}

ÖZ

Bu çalışmada, MINT ülkeleri olarak bilinen Meksika, Endonezya, Nijerya ve Türkiye enerji sektörünün global ölçekteki rekabet gücünün, 2000-2017 dönemi için, Ticaret Dengesi İndeksi (Trade Balance Index-TBI) ile ölçülmesi amaçlanmıştır. Enerji sektörüne ait dört alt sektörün rekabet gücü, Standart Uluslararası Ticaret Sinıflaması'na (Standard International Trade Classification -SITC Rev.3) göre iki dijitli veriler ile analiz edilmiştir. Çalışma, hem ulusal hem de uluslararası literatürde enerji sektörünün rekabet gücünün ölçülmesine yönelik olarak yapılan çalışma sayısının yetersiz olması ve literatürdeki bu boşluğun doldurulması, ayrıca Türkiye enerji sektörünün rekabet gücünün artırılabilmesi için politika önerilerinde bulunulması açısından önem arz etmektedir. İndeks sonuçlarına göre, Türkiye sadece 35 kodlu sektörde genel olarak net ihracatçı konumdayken, diğer sektörlerde net ithalatçı konumdadır. Meksika 33 ve 35 kodlu sektörlerde, Endonezya 32 , 33 ve 34 kodlu sektörlerde, Nijerya 33 ve 34 kodlu sektörlerde net ihracatçı konumdadır. MINT ülkeleri arasında enerji sektörünün rekabet gücü en düşük ülke Türkiye'dir. Meksika ülkesinin rekabet gücü Türkiye ile benzer ancak Türkiye'den daha iyi konumdadır. Rekabet gücü en yüksek ülkeler ise Nijerya ve Endonezya'dır.

Anahtar Kelimeler: Enerji Sektörü, Enerji Sektörü Alt Sektörleri, Ticaret Dengesi İndeksi, Rekabet Gücü, MINT Ülkeleri

\section{EVALUATION OF COMPETITIVENESS OF THE ENERGY SECTOR ON A GLOBAL SCALE: THE CASE OF MINT COUNTRIES}

\begin{abstract}
The aim of this study is to be measured the competitiveness of energy sector in a global scale for the 2000-2017 period with the Trade Balance Index (Trade Balance index-TBI) in MINT countries known as Mexico, Indonesia, Nigeria and Turkey. The competitiveness of the four sub-sectors of energy sector was analyzed with two-digit data according to the Standard International Trade Classification (SITC Rev.3). The study is important that in terms of filling this gap in the literature due to inadequate the number of studies conducted to measure the competitiveness of energy sector in both national and international literature, is also that important in terms of making in the policy recommendations to increase the competitiveness of energy sector in Turkey. According to the index results, while Turkey is a net exporter only in the 35 coded sector generally, it is a net importer in other sectors. Mexico is a net exporter in the 33, 35 and 34 coded sectors and 32, 33 and 34 coded sectors. Nigeria is a net exporter in the 33 and 34 coded sectors. Turkey has the lowest competitiveness in the energy sector among the countries MINT. Mexican's the competitiveness of energy sector is similar with Turkey, but it is better than Turkey's competitiveness of energy sector. Nigeria and Indonesia are the countries have the highest competitiveness in the energy sector.

Keywords: Energy Sector, Energy Sector Sub-Sectors, Trade Balance Index, Competitiveness, MINT Countries

1 Doç. Dr., Kayseri Üniversitesi, Meslek Yüksekokulu, Pazarlama ve Dış Ticaret Bölümü, batopcu@erciyes.edu.tr, ORCID: 0000-0003-2044-4568.

Received/Geliş: 25/04/2019 Accepted/Kabul:24/09/2019, Research Article/Araştırma Makalesi

Cite as/Alıntı: Altay Topcu, B. (2019), "Küresel Ölçekte Enerji Sektörünün Rekabet Gücünün Değerlendirilmesi: MINT Ülkeleri Örneği”, Çukurova Üniversitesi Sosyal Bilimler Enstitüsü Dergisi, cilt 28 , say1 2, s.272-285.
\end{abstract}




\section{Giriş}

Enerji, ülkelerin sosyal ve ekonomik gelişiminde önemli bir girdi kaynağıdır. Kömür, doğalgaz petrol vb. enerji kaynaklarının sınırlı olmasından dolayı, enerji kaynaklarının verimli kullanılması gerekmektedir. Buna yönelik olarak da ekonomi politikası uygulayıcılarının enerji kullanımı ile ilgili etkin politikalar üretmesi kaçınılmazdır. Büyük ölçekli sanayi tesislerinin üretim yapabilmesi için kullanması gereken en önemli girdi kaynaklarından birisi de enerjidir. Bu yolla bir üretim faktörü olarak kullanılan enerji girdisinin ülkelerin ekonomik büyümesine sağladığı katkı, enerjinin bir gelişmişlik ölçütü olarak kullanılmasına imkân vermiş̧ir.

Gelişmekte Olan Ülkelerde genel olarak enerji üretimi, enerji tüketimini karşılayamamaktadır. Petrol, doğalgaz ve elektrik gibi büyük öneme sahip girdiler üzerine konulan vergiler, üretim maliyetlerini artırıcı bir etki yaratmaktadır. Enerji maliyetlerinin artması ile sonuçlanan bu durum ülkeleri enerji sektöründe dışa bağımlı hale getirerek, ülkelerin rekabet gücünü olumsuz yönde etkilemektedir (Erdoğan ve Gürbüz, 2014, 79).

Enerjinin günlük yaşamdaki öneminin giderek artması ile birlikte, yaşamın sürdürülebilmesi için ihtiyaç duyulan enerjinin temin edilmesi de en önemli sorunlardan biri haline gelmiştir. Özellikle, ülkemizde olduğu gibi birincil enerji kaynaklarının temin edilmesi ithalata bağlıdır. Enerji sektörünün ithalata olan bağlılığ 1 ülke ekonomilerinde büyük dış ticaret açıkları ve dolayısıyla cari açık sorununu ortaya çıkarmaktadır. Gelişmekte Olan Ülkelerde gittikçe artan enerji ihtiyacının karşılanamamasının en önemli nedenlerinden biri de enerji yatırımlarının zamanında yapılamamasıdır (Ergün, 2005, 527-528).

Ekonomist Jim O'Neill tarafindan 2000'li yılların başında dünyanın en hızlı gelişen yükselen piyasaları olarak belirtilen BRIC (Brezilya, Rusya, Hindistan, Çin) grubu ülkelerinin son yıllarda performanslarının düşmesi nedeniyle, yeni piyasa arayışları gündeme gelmişsir. Bu sebeple O'Neill tarafindan 2013 yllı sonunda dünya ekonomisinin "Yeni Dörtlü"sü olarak belirtilen MINT (Meksika, Endonezya, Nijerya ve Türkiye) grubu ülkeleri ortaya çıkmıştır. Bu ülkelerin, özellikle demografik avantajları nedeniyle önümüzdeki 20 yıl için geleceğin ekonomileri arasında olacağı ifade edilmektedir (Hayaloğlu, 2015, 18).

Bu çalışmanın amacı, MINT ülkeleri örneğinde 2000-2017 dönemi için, SITC Rev.3 sınıflamasına göre iki dijitli veriler ile, enerji sektörüne ait dört alt sektörün rekabet gücünün analiz edilmesidir. Analiz yöntemi olarak TBI indeksi kullanılmıştır. Böylece sektörlerin net-ihracatcı ve net-ithalatcı konuma sahip olup olmadıkları söz konusu dönem itibariyle değerlendirilmiştir. Söz konusu sektörlerinin ihracatının rekabet gücünün analiz edilmesi, ilgili ülkelerde uygulanan ve uygulanması gereken etkin enerji politikalarının belirlenmesi gerekliliği açısından önem arz edecektir. Bu anlamda elde edilen analiz sonuçlarına göre, enerji sektörü MINT ülkelerinde özellikle de Türkiye ekonomisinde desteklenmesi gereken en önemli sektörlerden birisidir.

$\mathrm{Bu}$ çalışma dört bölümden oluşmaktadır. Çalışmanın birinci bölümünde, literatürde yer alan enerji sektörüne yönelik rekabet gücü çalışmaları ve diğer sektörlerin rekabet gücünün ölçülmesine yönelik olarak yapılan ampirik çalışmalara yer verilmiştir. İkinci bölümde, çalışmada kullanılan yöntem olan Ticaret Dengesi İndeksi (Trade Balance Index-TBI) ve analizde kullanılan veriler açıklanmıştır. Üçüncü bölümde, enerji 
Ç.Ü. Sosyal Bilimler Enstitüsü Dergisi, Cilt 28, Sayı 2, 2019, Sayfa 272-285

alt sektörlerine ait analiz sonuçları sunulmuştur. Çalışma sonuç bölümü ile tamamlanmıştır.

\section{Literatür Araştırması}

Ampirik literatürde, hem ulusal hem de uluslararası düzeyde ülkelerin dış ticarette rekabet gücünün ölçümüne yönelik olarak Açıklanmış Karşılaştırmalı Üstünlük İndeksleri yardımıyla sektörel düzeyde yapılmış çalışma sayısı oldukça fazladır. Ancak enerji sektörünün rekabet gücü ölçümüne yönelik çalışma sayısı yetersizdir. Rekabet gücü ölçümüne yönelik literatürde yapılan çalışmaların bazıları aşağıdaki gibidir:

Widodo (2016), ASEAN (Güneydoğu Asya Ülkeleri Birliği) ülkelerinin enerji sektörünün rekabet gücünü, enerji sektörü verilerinin elde edilebilirliğine göre farklı yıllar için, Ticaret Dengesi indeksi ile ölçmüştür. Çalışma sonuçlarına göre, ASEAN ülkeleri SITC 333 kodlu ürünler (kömür, linyit ve turba) ve SITC 341 kodlu ürünlerde (gaz, doğal gaz ve diğer mamul gazlar) en fazla rekabetçi üstünlüğe sahipken; SITC 332 kodlu ürünlerde (briketler, kok ve yarı kok, linyit veya turba, imbik karbon) en az rekabetçi üstünlüğe sahiptir.

Kuşat (2018), AB 28 ülkelerinin ve AB'ye aday ülkelerin SITC Rev.3 sınıflamasına göre enerji sektörü rekabet gücünü 2006-2016 yılları için analiz etmiştir. Çalışmada Balassa (1965)'in Açıklanmış Karşılaştırmalı Üstünlükler İndeksi kullanılmıştır. Çalışmadan elde edilen bulgulara göre, enerji sektörünün geneli için 2006 yılında sadece Karadağ ve Arnavutluk ekonomisi enerji sektöründe yüksek bir rekabet gücüne sahiptir. AB'ye aday diğer ülkeler ise enerji sektörünün geneli göz önüne alındığında rekabetçi dezavantaja sahiptir.

Altay ve Gürpınar (2008), Türkiye'nin mobilya sektörünün uluslararası rekabet gücünü, Açıklanmış Karşılaştırmalı Üstünlükler İndeksi, Göreli İhracat Avantaj İndeksi, Göreli İthalat Avantaj İndeksi ve Göreli Ticaret Avantaj İndeksleri ile 2001-2006 dönemi için ölçmüşlerdir. Genel olarak indeks sonuçlarına göre, Türkiye mobilya sektöründe uluslararası alanda rekabetçi avantaja sahiptir. Çalışmada ayrıca Türkiye'nin mobilya sektörünün AB karşısındaki rekabet gücü İhracatta Uzmanlaşma İndeksi ile aynı dönem için ölçülmüştür. Elde edilen bulgulara göre, Türkiye ekonomisi mobilya sektöründe $\mathrm{AB}$ karşısında rekabetçi dezavantaja sahiptir.

Ardıç (2017), Açıklanmış Karşılaştırmalı Üstünlükler İndeksi ile Türkiye’nin ihracat yaptığı sektörlerin rekabet gücünü 2005-2016 yılları için hesaplamıştır. Çalışmada elde edilen sonuçlara göre, Türkiye'nin bitkisel ürünler, gıda sanayi ürünleri, tekstil ürünleri, cam ve cam eşya, metaller, araçlar fasıllarında ihracatta karşılaştırmalı üstünlüğe sahip olduğu belirlenmiştir.

Çakmak (2005), Türkiye tekstil ve hazır giyim sektörünün rekabet gücünü, Balassa'nın Açıklanmış Karşılaştırmalı Üstünlük İndeksi ve Volrath İndeskleri ile 19892003 yılları için analiz etmiştir. İndeks sonuçlarına göre, Türkiye SITC 84 kodlu ürünlerde (konfeksiyon ve aksesuarları) ve SITC 65 kodlu ürünlerde (dokumacılık ürünleri) açıklanmış karşılaştırmalı üstünlüğe sahiptir. Ancak son yıllarda, genel olarak tüm ürün gruplarının rekabet gücünde önemli düşüşler ortaya çıkmıştır.

Erkan ve Batbaylı (2017), KEİ’nin (Karadeniz Ekonomik İşbirliği Örgütü) rekabet gücünü 2000-2014 yılları için Balassa İndeksi ve Volrath İndeksleri ile ölçmüşlerdir. Çalışmadan elde edilen bulgulara göre, KEİ ülkeleri hammadde ve emek yoğun ürünlerin 
ihracatında karşılaştırmalı üstünlüğe sahipken, ar-ge ve teknoloji yoğun ürünlerin ihracatında küresel pazarlarda rekabetçi dezavantaja sahiptir.

Rossato vd. (2018), ahşap hamuru üretiminin rekabet gücünü Amerika Birleșik Devletleri, Brezilya, Kanada, İsveç, Finlandiya ve Çin ekonomileri için ölçmüşlerdir. Rekabet gücü ölçümünde Açıklanmış Karşılaştırmalı Üstünlük İndeksi, Açıklanmış Simetrik Karşılaştırmalı Üstünlük İndeksi ve Ticaret Dengesi indekslerini kullanmışlardır. AKÜ indeks sonuçlarına göre, Çin dışında tüm ülkeler söz konusu üründe karşılaştırmalı üstünlüğe sahiptir. Açıklanmış Simetrik Karşılaştırmalı Üstünlük İndeks sonuçlarına göre Finlandiya, Kanada ve İsveç en yüksek karşılaştırmalı üstünlüğe sahip ülkelerdir. TBI indeks sonuçlarına göre ise söz konusu üründe Brezilya, Finlandiya, Kanada, İsveç ve ABD net ihracatçı ve karşılaştırmalı üstünlüğe sahiptir. Ancak Çin net ithalatçı ve karşılaştırmalı dezavantaja sahiptir.

Arastou (2008), Kazakistan'ın AB-27'ye yapılan dünya ihracatının SITC sınıflamasında yer alan tüm sektörlerin rekabet gücünü, 1999-2006 yılları için analiz etmiştir. Ampirik analiz Balassa'nın Açıklanmış Karşılaştırmalı Üstünlük İndeksi'ne dayanmaktadır. Kazakistan’ın enerji sektörü, tekstil sektörü, kimyasal ürünler ve demirçelik ürünlerinin bazı alt sektörlerinde açıklanmış karşılaştırmalı üstünlük göstermesine rağmen, rekabet edebilirliğinin neredeyse tüm sektörlerde düşüş eğiliminde olduğu sonucuna ulaşılmıştır.

Startiene ve Remeikiene (2014), 2007-2011 yılları için, Litvanya'nın sanayi sektörünün rekabet gücünü analiz etmişlerdir. Rekabet gücünü, Açıklanmış Karşılaştırmalı Üstünlükler ve Açıklanmış Simetrik Karşılaştırmalı Üstünlükler İndekslerini kullanarak ölçmüşlerdir. İndeks sonuçlarına göre, Litvanya 2007-2011 yıllarında özellikle gıda, kimyasal, ahşap ve tekstil ürünlerinde dünya ölçeğinde en güçlü rekabet pozisyonuna sahiptir.

\section{Veri ve Yöntem}

Çalışmada MINT ülkelerinin enerji sektörünün rekabet gücü, TBI indeksi yardımıyla SITC Rev.3 sınıflamasına göre iki dijitli veriler ile, 2000-2017 dönemi için ölçülmüştür. MINT ülkelerine ait enerji sektörü verileri Birleşmiș Milletlerin Uluslararası Ticaret İstatistikleri veri tabanından elde edilmiştir (UN Comtrade, International Trade Statistics Database).

Çalışmada analiz edilen enerji sektörü kodları ve tanımları Tablo 1'de verilmiştir. Birleşmiş Milletlerin Uluslararası Ticaret İstatistikleri veri tabanında SITC Rev.3 sınıflamasına göre enerji sektörü 3 nolu başlıkta verilmiştir. Bu çalışmada enerji sektörünün rekabet gücünün genel durumunu analiz etmek için 3 nolu koda ait veriler kullanılmıştır. Ayrıca iki dijitli enerji sektörü alt sektörleri analize dâhil edilmiştir.

Tablo 1. Enerji Sektör Kodları ve Tanımları

\begin{tabular}{|c|l|}
\hline Sektör Kodları & \multicolumn{1}{c|}{ Sektör Tanımları } \\
\hline $\mathbf{3}$ & Mineral Yakıtlar, Yağlar ve Alkali Ürünler \\
\hline $\mathbf{3 2}$ & Kömür, Kok Kömürü ve Briketler \\
\hline $\mathbf{3 3}$ & Petrol, Petrol Ürünleri ve İlgili Malzemeler \\
\hline $\mathbf{3 4}$ & Petrol Gazları, Doğal Gaz ve Diğer Mamul Gazlar \\
\hline $\mathbf{3 5}$ & Elektrik Enerjisi \\
\hline
\end{tabular}


Ampirik literatürde rekabet gücü ölçümlerinde genel olarak Balassa (1965) tarafından geliştirilen Açıklanmış Karşılaştırmalı Üstünlük (Revealed Comparative Advantage-RCA) İndeksi ve Vollrath (1991) tarafindan geliştirilen Açıklanmış İhracat Avantajı (Revealed Export Advantage-RXA) ve Açıklanmış İthalat Avantajı (Revealed Import Advantage-RMA) İndeksleri kullanılmaktadır. Son dönemlerde yapılan çalışmalarda bu indekslerin yanı sıra Dalum, Laursen ve Villumsen (1998) tarafindan geliştirilen ve Balassa İndeksi'ne farklı bir yorum katan Açıklanmış Simetrik Karşılaştırmalı Üstünlük (Revealed Symmetric Comparative Advantage-RSCA) İndeksi kullanılmaktadır.

Ayrıca Lafay (1992) tarafından geliştirilen Ticaret Dengesi İndeksi (Trade Balance Index-TBI) kullanılan diğer bir indekstir. Söz konusu indeks ilgili ülkenin ticaret dengesini (net ithalatçı-net ihracatçı olup olamama durumunu) analiz etmektedir. Dolayısıyla bu indeks, ülkenin ticaret dengesinin belirlenmesi ile rekabetçi üstünlük durumunu da ortaya koymakta ve bu açıdan en kapsamlı indeks olarak karşımıza çıkmaktadır. Bu nedenle, çalışmada MINT ülkelerinin enerji sektörünün rekabet gücü TBI indeksi ile ölçülmüştür.

Lafay (1992) tarafından geliştirilen TBI indeksi, bir ülkenin belirli bir ürün grubunda, net ihracatçı veya net ithalatçı olup olmadığını göstermektedir. TBI indeksi aşağıdaki gibi formüle edilmektedir:

$$
T B I i_{j}=\left(X_{i j}-M_{i j}\right) /\left(X_{i j}+M_{i j}\right)
$$

1 nolu denklemde $T B I i_{j}$, ilgili ülkelerin $j$ sektörü için Ticaret Dengesi İndeksi'ni, $M, j$ sektöründeki ithalat değerini, $X, j$ sektöründeki ihracat değerini göstermektedir. TBI indeksi -1 ile +1 arasında bir değer almaktadır. Ĕger indeks değeri -1 ise, ilgili ülkenin $j$ sektöründe yalnızca ithalatçı olduğu, eğer indeks değeri +1 ise, ilgili ülkenin j sektöründe yalnızca ihracatçı olduğu söylenir. İndeks değerinin 0'a eşit olması ise ilgili ülkenin j sektörüne ait ihracat ve ithalat değerlerinin birbirine eşit olduğunu gösterir. İndeks değerlerinin $-1,+1$ ve 0 değerlerini alması, ilgili ülkenin genellikle ilgili sektörde hem ihracatçı hem de ithalatçı olmasından dolayı çok fazla mümkün olmayan bir durumdur. $\mathrm{Bu}$ yüzden TBI indeksinin negatif değerler alması durumunda ilgili ülke net ithalatçı, pozitif değerler alması durumunda ise net ihracatçı olarak yorumlanmaktadır (Altay Topcu ve Sümerli Sarıül, 2015, 336).

\section{Enerji Sektörü Rekabet Gücü Analiz Sonuçları}

Çalışmanın bu bölümünde ilk olarak MINT ülkelerinin enerji sektörüne ait alt sektörlerin rekabet gücü analiz sonuçları değerlendirilmiştir. Daha sonra söz konusu ülkelerin enerji sektörünün rekabet gücü genel durumu analiz edilmiştir.

\section{Enerji Sektörüne Ait Alt Sektörlerin Rekabet Gücü Analizi}

Çalışmanın bu kısmında MINT ülkelerinin enerji sektörü alt sektörleri TBI indeks değerleri ve bu değerlerin grafiksel gösterimi ile değerlendirilmiştir.

\section{Türkiye Enerji Sektörü Rekabet Gücü Analiz Sonuçları}

Türkiye ekonomisi için TBI indeks sonuçları Tablo 2 ve Şekil 1'de gösterilmiştir. Tablo 2 ve Şekil 1'de görüldüğü gibi, 2000-2017 dönemi için Türkiye ekonomisi 32, 33 ve 34 kodlu sektörlerde karşılaştırmalı dezavantaja sahip ve net ithalatçı konumda iken, 35 kodlu üründe ise 2004-2011 dönemi için karşılaştırmalı üstünlüğe sahip ve net ihracatçı 
Ç.Ü. Sosyal Bilimler Enstitüsü Dergisi, Cilt 28, Sayı 2, 2019, Sayfa 272-285

konumdadır. 35 kodlu üründe diğer yıllarda karşılaştırmalı dezavantaja sahip ve net ithalatçı konumdadır.

Tablo 2. Türkiye Enerji Sektörü TBI İndeks Sonuçları

\begin{tabular}{|l|c|c|c|c|}
\hline \multirow{2}{*}{ Ylllar } & \multicolumn{4}{|c|}{ Sektörler } \\
\cline { 2 - 5 } & $\mathbf{3 2}$ & $\mathbf{3 3}$ & $\mathbf{3 4}$ & $\mathbf{3 5}$ \\
\hline $\mathbf{2 0 0 0}$ & $-0,9939$ & $-0,9127$ & $-0,9736$ & $-0,7319$ \\
\hline $\mathbf{2 0 0 1}$ & $-0,9779$ & $-0,8427$ & $-0,9566$ & $-0,7758$ \\
\hline $\mathbf{2 0 0 2}$ & $-0,9958$ & $-0,7840$ & $-0,9552$ & $-0,7801$ \\
\hline $\mathbf{2 0 0 3}$ & $-0,9970$ & $-0,7785$ & $-0,7508$ & $-0,3677$ \\
\hline $\mathbf{2 0 0 4}$ & $-0,9961$ & $-0,772$ & $-0,6406$ & $\mathbf{0 , 5 8 6 5}$ \\
\hline $\mathbf{2 0 0 5}$ & $-0,9942$ & $-0,7192$ & $-0,5304$ & $\mathbf{0 , 7 0 0 7}$ \\
\hline $\mathbf{2 0 0 6}$ & $-0,9975$ & $-0,6718$ & $-0,8049$ & $\mathbf{0 , 7 4 3 2}$ \\
\hline $\mathbf{2 0 0 7}$ & $-0,9905$ & $-0,5999$ & $-0,869$ & $\mathbf{0 , 7 7 3 9}$ \\
\hline $\mathbf{2 0 0 8}$ & $-0,9536$ & $-0,2278$ & $-0,8016$ & $\mathbf{0 , 6 5 1 1}$ \\
\hline $\mathbf{2 0 0 9}$ & $-0,9968$ & $-0,4199$ & $-0,7809$ & $\mathbf{0 , 7 8 0 2}$ \\
\hline $\mathbf{2 0 1 0}$ & $-0,9886$ & $-0,4777$ & $-0,8774$ & $\mathbf{0 , 7 9 7 1}$ \\
\hline $\mathbf{2 0 1 1}$ & $-0,9910$ & $-0,4333$ & $-0,8566$ & $\mathbf{0 , 2 6 4 2}$ \\
\hline $\mathbf{2 0 1 2}$ & $-0,9889$ & $-0,3981$ & $-0,8063$ & $-0,1463$ \\
\hline $\mathbf{2 0 1 3}$ & $-0,9891$ & $-0,4460$ & $-0,8222$ & $-0,8406$ \\
\hline $\mathbf{2 0 1 4}$ & $-0,9784$ & $-0,4834$ & $-0,8717$ & $-0,6633$ \\
\hline $\mathbf{2 0 1 5}$ & $-0,9906$ & $-0,3989$ & $-0,8658$ & $-0,6298$ \\
\hline $\mathbf{2 0 1 6}$ & $-0,9951$ & $-0,4505$ & $-0,8746$ & $-0,8804$ \\
\hline $\mathbf{2 0 1 7}$ & $-0,9942$ & $-0,4610$ & $-0,8509$ & $-0,0217$ \\
\hline
\end{tabular}

Kaynak: Yazar tarafından hesaplanmıştır.

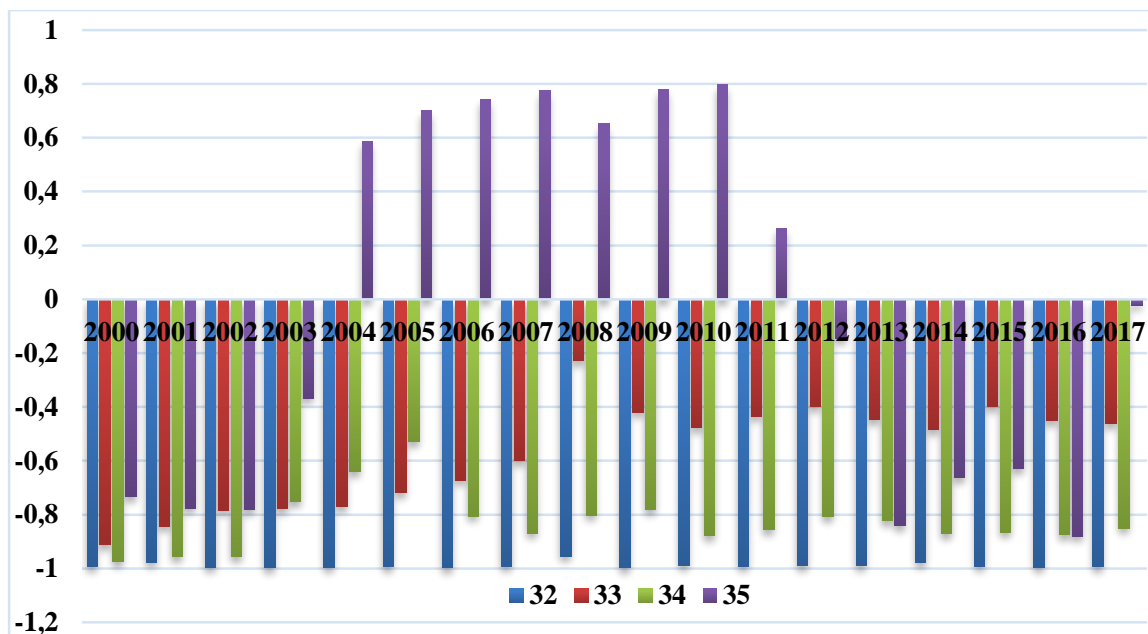

Şekil 1. Türkiye Enerji Sektörü TBI İndeks Değerleri Grafiği Kaynak: Yazar tarafindan oluşturulmuştur. 
Ç.Ü. Sosyal Bilimler Enstitüsü Dergisi, Cilt 28, Sayı 2, 2019, Sayfa 272-285

Meksika Enerji Sektörü Rekabet Gücü Analiz Sonuçları

Meksika ekonomisi için TBI indeks sonuçları Tablo 3 ve Şekil 2'de gösterilmiştir.

Tablo 3. Meksika Enerji Sektörü TBI İndeks Sonuçları

\begin{tabular}{|c|c|c|c|c|}
\hline \multirow{2}{*}{ Ylllar } & \multicolumn{4}{|c|}{ Sektörler } \\
\cline { 2 - 5 } & $\mathbf{3 2}$ & $\mathbf{3 3}$ & $\mathbf{3 4}$ & $\mathbf{3 5}$ \\
\hline $\mathbf{2 0 0 0}$ & $-0,9865$ & $\mathbf{0 , 6 4 1 8}$ & $-0,8997$ & $-0,6149$ \\
\hline $\mathbf{2 0 0 1}$ & $-0,9924$ & $\mathbf{0 , 5 7 1 2}$ & $-0,8613$ & $-0,5034$ \\
\hline $\mathbf{2 0 0 2}$ & $-0,9872$ & $\mathbf{0 , 6 9 6 3}$ & $-0,9740$ & $\mathbf{0 , 1 2 9 0}$ \\
\hline $\mathbf{2 0 0 3}$ & $-0,9949$ & $\mathbf{0 , 7 5 4}$ & $-0,9879$ & $\mathbf{0 , 8 3 5 0}$ \\
\hline $\mathbf{2 0 0 4}$ & $-0,9960$ & $\mathbf{0 , 7 2 8 3}$ & $-0,9973$ & $\mathbf{0 , 8 3 5 2}$ \\
\hline $\mathbf{2 0 0 5}$ & $-0,9964$ & $\mathbf{0 , 6 0 8 5}$ & $-0,9634$ & $\mathbf{0 , 9 5 8 8}$ \\
\hline $\mathbf{2 0 0 6}$ & $-0,9935$ & $\mathbf{0 , 5 8 7 0}$ & $-0,9376$ & $\mathbf{0 , 6 9 4 0}$ \\
\hline $\mathbf{2 0 0 7}$ & $-0,9832$ & $\mathbf{0 , 4 8 6 9}$ & $-0,8490$ & $\mathbf{0 , 8 0 4 3}$ \\
\hline $\mathbf{2 0 0 8}$ & $-0,9701$ & $\mathbf{0 , 3 9 0 7}$ & $-0,9220$ & $\mathbf{0 , 7 3 8 7}$ \\
\hline $\mathbf{2 0 0 9}$ & $-0,9797$ & $\mathbf{0 , 4 2 6 3}$ & $-0,9091$ & $\mathbf{0 , 8 2 3 0}$ \\
\hline $\mathbf{2 0 1 0}$ & $-0,9671$ & $\mathbf{0 , 3 6 3 6}$ & $-0,9104$ & $\mathbf{0 , 7 7 8 1}$ \\
\hline $\mathbf{2 0 1 1}$ & $-0,9404$ & $\mathbf{0 , 3 1 6 0}$ & $-0,9665$ & $\mathbf{0 , 7 4 1 7}$ \\
\hline $\mathbf{2 0 1 2}$ & $-0,9385$ & $\mathbf{0 , 2 9 5 0}$ & $-0,9979$ & $\mathbf{0 , 4 0 8 6}$ \\
\hline $\mathbf{2 0 1 3}$ & $-0,9953$ & $\mathbf{0 , 2 9 5 6}$ & $-0,9975$ & $\mathbf{0 , 4 7 8 7}$ \\
\hline $\mathbf{2 0 1 4}$ & $-0,9968$ & $\mathbf{0 , 2 4 3 4}$ & $-0,9941$ & $\mathbf{0 , 5 7 1 4}$ \\
\hline $\mathbf{2 0 1 5}$ & $-0,9969$ & $\mathbf{0 , 0 3 9 0}$ & $-0,9990$ & $\mathbf{0 , 3 6 1 5}$ \\
\hline $\mathbf{2 0 1 6}$ & $-0,9974$ & $-0,0193$ & $-0,9894$ & $\mathbf{0 , 2 8 5 9}$ \\
\hline $\mathbf{2 0 1 7}$ & $-0,9700$ & $-0,0683$ & $-0,9906$ & $-0,1091$ \\
\hline
\end{tabular}

Kaynak: Yazar tarafindan hesaplanmıştır.

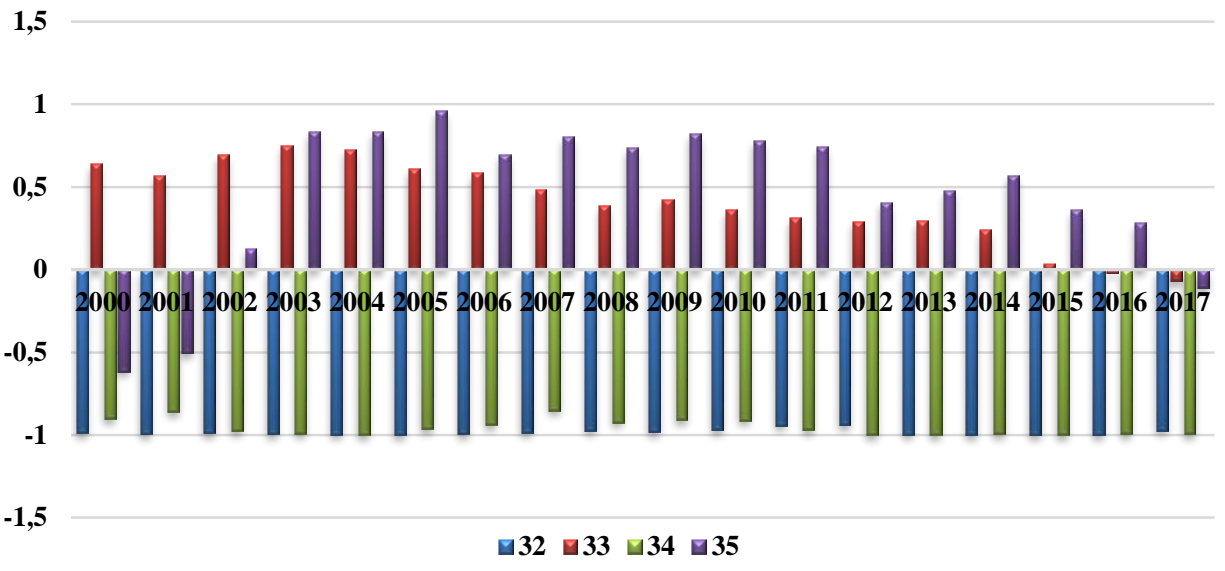

Şekil 2. Meksika Enerji Sektörü TBI İndeks Değerleri Grafiği Kaynak: Yazar tarafindan oluşturulmuştur. 
Tablo 3 ve Şekil 2'de görüldüğü gibi, Meksika ekonomisi 2000-2017 dönemi için 32 ve 34 kodlu sektörlerde karşılaştırmalı dezavantaja sahip ve net ithalatçı konumda iken, 33 kodlu sektörde 2000-2015 döneminde karşılaştırmalı üstünlüğe sahip ve net ihracatçı konumdadır. Bu üstünlüğünü 2016 ve 2017 yılları için yitirmiştir. 35 kodlu sektörde ise 2002-2016 döneminde karşılaştırmalı üstünlüğe sahip ve net ihracatçı konumdadır. Bu sektörde diğer yıllar için karşılaştırmalı dezavantaja sahip ve net ithalatçı konumdadir.

\section{Endonezya Enerji Sektörü Rekabet Gücü Analiz Sonuçları}

Endonezya ekonomisi için TBI indeks sonuçları Tablo 4 ve Şekil 3'de gösterilmiştir. Tablo 4 ve Şekil 3'de görüldüğü gibi, Endonezya ekonomisi, 2000-2017 dönemi için 32 ve 34 kodlu sektörlerde karşılaştırmalı üstünlüğe sahip ve net ihracatçı konumda iken, 33 kodlu sektörde 2000-2002 dönemi için karşılaştırmalı dezavantaja sahip ve net ithalatçı konumdadır. Ancak söz konusu sektörde, 2003-2017 döneminde karşılaştırmalı üstünlüğe sahip ve net ihracatçı konumdadır. 35 kodlu sektörde ise veri eksikliği nedeniyle hesaplanan 2003 ve 2006 yılları için sırasıyla net ithalatçı ve net ihracatçı konumdadir.

Tablo 4. Endonezya Enerji Sektörü TBI İndeks Sonuçları

\begin{tabular}{|c|c|c|c|c|}
\hline \multirow{2}{*}{ Yillar } & \multicolumn{4}{|c|}{ Sektörler } \\
\cline { 2 - 5 } & $\mathbf{3 2}$ & $\mathbf{3 3}$ & $\mathbf{3 4}$ & $\mathbf{3 5}$ \\
\hline $\mathbf{2 0 0 0}$ & $\mathbf{0 , 9 8 0 6}$ & $\mathbf{0 , 1 2 3 5}$ & $\mathbf{0 , 9 9 8 9}$ & $*$ \\
\hline $\mathbf{2 0 0 1}$ & $\mathbf{0 , 9 8 7 4}$ & $\mathbf{0 , 1 1 3 8}$ & $\mathbf{0 , 9 9 6 5}$ & $*$ \\
\hline $\mathbf{2 0 0 2}$ & $\mathbf{0 , 9 8 9 8}$ & $\mathbf{0 , 0 0 0 9}$ & $\mathbf{0 , 9 9 9 9}$ & $*$ \\
\hline $\mathbf{2 0 0 3}$ & $\mathbf{0 , 9 8 6 8}$ & $-0,0274$ & $\mathbf{0 , 9 9 3 4}$ & $-0,8868$ \\
\hline $\mathbf{2 0 0 4}$ & $\mathbf{0 , 9 7 9 0}$ & $-0,1871$ & $\mathbf{0 , 9 9 7 8}$ & $*$ \\
\hline $\mathbf{2 0 0 5}$ & $\mathbf{0 , 9 8 8 8}$ & $-0,2624$ & $\mathbf{0 , 9 9 6 8}$ & \\
\hline $\mathbf{2 0 0 6}$ & $\mathbf{0 , 9 9 2 8}$ & $-0,2520$ & $\mathbf{0 , 9 9 4 1}$ & $\mathbf{0 , 9 7 1 5}$ \\
\hline $\mathbf{2 0 0 7}$ & $\mathbf{0 , 9 9 4 0}$ & $-0,2717$ & $\mathbf{0 , 9 8 2 3}$ & $*$ \\
\hline $\mathbf{2 0 0 8}$ & $\mathbf{0 , 9 9 1 0}$ & $-0,3059$ & $\mathbf{0 , 9 6 1 1}$ & $*$ \\
\hline $\mathbf{2 0 0 9}$ & $\mathbf{0 , 9 9 4 0}$ & $-0,2907$ & $\mathbf{0 , 8 9 6 2}$ & $*$ \\
\hline $\mathbf{2 0 1 0}$ & $\mathbf{0 , 9 9 5 8}$ & $-0,2917$ & $\mathbf{0 , 8 8 1 2}$ & $*$ \\
\hline $\mathbf{2 0 1 1}$ & $\mathbf{0 , 9 9 6 9}$ & $-0,3534$ & $\mathbf{0 , 8 8 3 7}$ & $*$ \\
\hline $\mathbf{2 0 1 2}$ & $\mathbf{0 , 9 9 4 9}$ & $-0,4072$ & $\mathbf{0 , 7 3 8 9}$ & $*$ \\
\hline $\mathbf{2 0 1 3}$ & $\mathbf{0 , 9 8 9 9}$ & $-0,4826$ & $\mathbf{0 , 7 0 6 9}$ & $*$ \\
\hline $\mathbf{2 0 1 4}$ & $\mathbf{0 , 9 6 6 1}$ & $-0,5113$ & $\mathbf{0 , 7 0 0 6}$ & $*$ \\
\hline $\mathbf{2 0 1 5}$ & $\mathbf{0 , 9 6 0 0}$ & $-0,4639$ & $\mathbf{0 , 6 7 4 1}$ & $*$ \\
\hline $\mathbf{2 0 1 6}$ & $\mathbf{0 , 9 4 5 4}$ & $-0,4616$ & $\mathbf{0 , 6 1 6 6}$ & $*$ \\
\hline $\mathbf{2 0 1 7}$ & $\mathbf{0 , 9 0 8 6}$ & $-0,5234$ & $\mathbf{0 , 5 0 7 3}$ & $*$ \\
\hline
\end{tabular}

Kaynak: Yazar tarafindan hesaplanmıștır.

*Söz konusu yıllara ait sektör ihracat verileri mevcut olmadığ 
Ç.Ü. Sosyal Bilimler Enstitüsü Dergisi, Cilt 28, Sayı 2, 2019, Sayfa 272-285

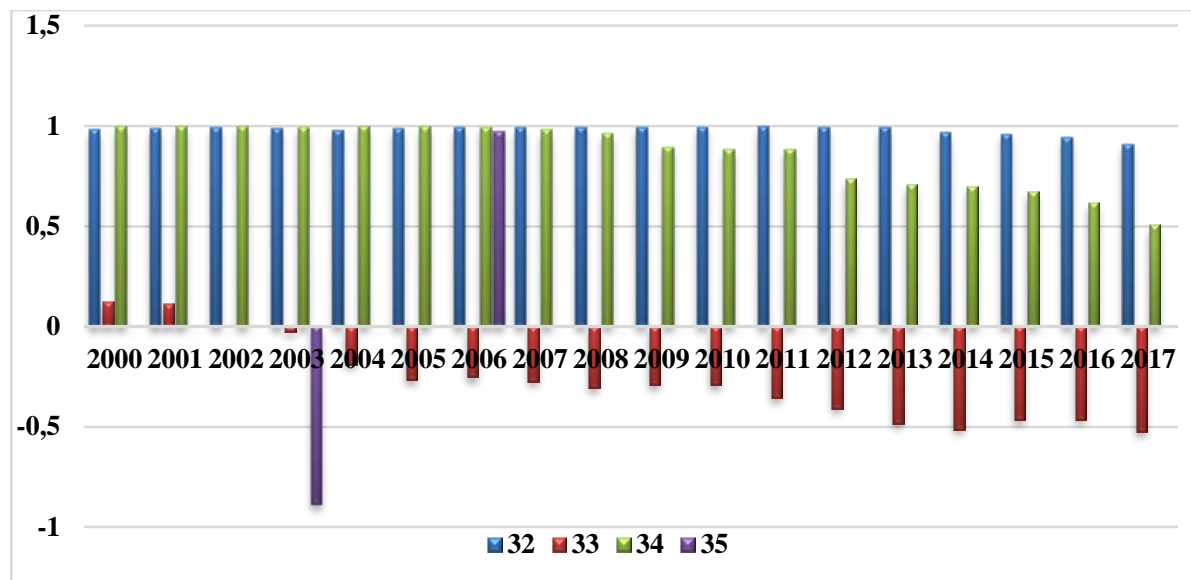

Şekil 3. Endonezya Enerji Sektörü TBI İndeks Değerleri Grafiği Kaynak: Yazar tarafindan oluşturulmuştur.

Nijerya Enerji Sektörü Rekabet Gücü Analiz Sonuçları

Nijerya ekonomisi için TBI indeks sonuçları Tablo 5 ve Şekil 4'de gösterilmiştir.

Tablo 5. Nijerya Enerji Sektörü TBI İndeks Sonuçları

\begin{tabular}{|c|c|c|c|c|}
\hline \multirow{2}{*}{ YIllar } & \multicolumn{4}{|c|}{ Sektörler } \\
\cline { 2 - 5 } & $\mathbf{3 2}$ & $\mathbf{3 3}$ & $\mathbf{3 4}$ & $\mathbf{3 5}$ \\
\hline $\mathbf{2 0 0 0}$ & $*$ & $\mathbf{0 , 9 9 3 1}$ & $\mathbf{0 , 8 1 8 4}$ & $*$ \\
\hline $\mathbf{2 0 0 1}$ & $*$ & $\mathbf{0 , 9 8 1 7}$ & $\mathbf{0 , 9 6 3 5}$ & $*$ \\
\hline $\mathbf{2 0 0 3}$ & $-0,9985$ & $\mathbf{0 , 9 8 6 7}$ & $\mathbf{0 , 9 9 4 4}$ & $*$ \\
\hline $\mathbf{2 0 0 4}$ & $*$ & $*$ & $-0,2113$ & $*$ \\
\hline $\mathbf{2 0 0 5}$ & $*$ & $*$ & $*$ & $*$ \\
\hline $\mathbf{2 0 0 6}$ & $*$ & $\mathbf{0 , 9 7 8 7}$ & $*$ & $*$ \\
\hline $\mathbf{2 0 0 7}$ & $-0,1956$ & $\mathbf{0 , 9 7 8 2}$ & $\mathbf{0 , 8 9 7 5}$ & $*$ \\
\hline $\mathbf{2 0 0 8}$ & $*$ & $\mathbf{0 , 9 8 8 7}$ & $\mathbf{0 , 8 8 5 8}$ & $*$ \\
\hline $\mathbf{2 0 0 9}$ & $*$ & $\mathbf{0 , 9 8 4 5}$ & $\mathbf{0 , 9 9 7 6}$ & $*$ \\
\hline $\mathbf{2 0 1 0}$ & $*$ & $\mathbf{0 , 9 8 3 8}$ & $\mathbf{0 , 9 9 8 9}$ & $*$ \\
\hline $\mathbf{2 0 1 1}$ & $\mathbf{0 , 8 2 7 7}$ & $\mathbf{0 , 8 9 0 1}$ & $\mathbf{0 , 9 4 0 9}$ & $-0,9656$ \\
\hline $\mathbf{2 0 1 2}$ & $-0,7720$ & $\mathbf{0 , 9 8 5 0}$ & $\mathbf{0 , 9 9 9 0}$ & \\
\hline $\mathbf{2 0 1 3}$ & $\mathbf{0 , 5 7 8 3}$ & $\mathbf{0 , 7 9 2 0}$ & $\mathbf{0 , 9 9 2 0}$ & \\
\hline $\mathbf{2 0 1 4}$ & $-0,9943$ & $\mathbf{0 , 8 2 9 6}$ & $\mathbf{0 , 9 9 9 9}$ & $-0,9968$ \\
\hline $\mathbf{2 0 1 5}$ & $*$ & $*$ & $*$ & $\mathbf{0 , 9 9 9 9}$ \\
\hline $\mathbf{2 0 1 6}$ & $*$ & $\mathbf{0 , 4 6 0 0}$ & $\mathbf{0 , 9 9 9 5}$ & $\mathbf{0 , 9 9 8 6}$ \\
\hline $\mathbf{2 0 1 7}$ & $-0,9734$ & $\mathbf{0 , 6 1 3 6}$ & $\mathbf{0 , 9 9 9 7}$ & $\mathbf{0 , 9 9 2 2}$ \\
\hline
\end{tabular}

*Söz konusu yıllara ait sektör ihracat ve ithalat verileri mevcut olmadığı için TBI indeks değerleri hesaplanamamıştır. 
Tablo 5 ve Şekil 4'de görüldüğü gibi, Nijerya ekonomisi, 33 ve 34 kodlu sektörlerde verisi mevcut olan yılların genelinde karşılaştırmalı üstünlüğe sahip ve net ihracatçı konumdadır. 32 kodlu sektörde, verisi mevcut olan 2011 ve 2013 yıllarında net ihracatçı konumdayken, 2003, 2007 ve 2012 yıllarında net ithalatçı konumdadır. 35 kodlu sektörde ise verisi mevcut olan 2016 ve 2017 yıllarında net ihracatçı ve 2011 ve 2014 yıllarında net ithalatçı konumdadır.

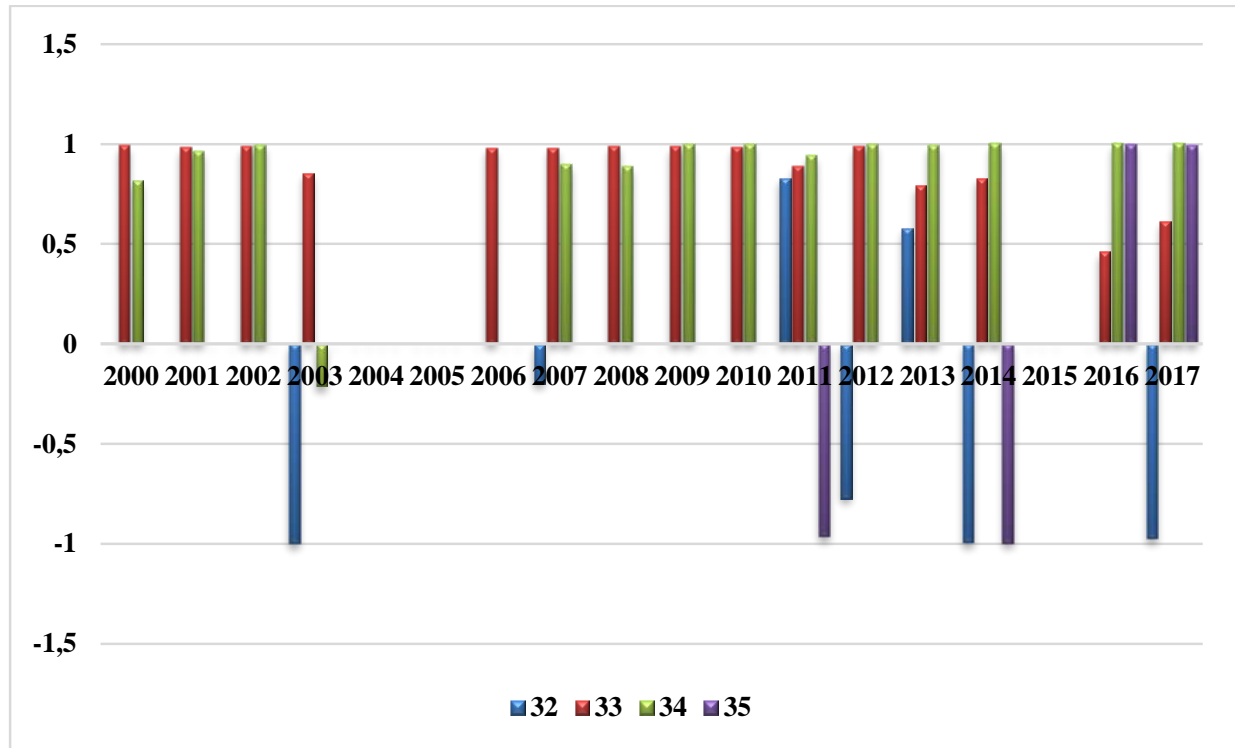

Şekil 4. Nijerya Enerji Sektörü TBI İndeks Değerleri Grafiği Kaynak: Yazar tarafindan oluşturulmuştur.

\section{MINT Ülkeleri Enerji Sektörü Rekabet Gücü}

\section{Genel Durumuna İlişkin Analiz Sonuçları}

Tablo 6 ve Şekil 5'de MINT ülkelerinin enerji sektörü TBI indeks sonuçları, sektör alt dijitlerine ayrılmadan gösterilmiştir. Verilerin elde edilebilirliğine göre de 2006-2017 dönemi esas alınmıştır. Tablo 6 ve Şekil 5'de görüldüğü gibi, Türkiye ekonomisi yıllar itibariyle enerji sektöründe net ithalatçı konumdadır. Elde edilen sonuçlara göre enerji sektöründe rekabet gücü olmadığı söylenebilir. Meksika ekonomisi enerji sektöründe 2006-2014 döneminde net ihracatçı konumdayken, sektördeki rekabet gücünü son yıllarda yitirmiştir. Endonezya ve Nijerya ekonomisi ise yıllar itibariyle enerji sektöründe net ihracatçı konumda olup, Türkiye ve Meksika ile karşılaştırıldığında enerji sektöründeki rekabet gücü daha yüksektir. 
Ç.Ü. Sosyal Bilimler Enstitüsü Dergisi, Cilt 28, Sayı 2, 2019, Sayfa 272-285

Tablo 6. MINT Ülkeleri Enerji Sektörü (SITC REV.3, 3 Kodlu Sektör) TBI İndeks Sonuçları (2006-2017 Dönemi)

\begin{tabular}{|c|c|c|c|c|}
\hline \multirow{2}{*}{ Yıllar } & \multicolumn{4}{|c|}{ Ülkeler } \\
\cline { 2 - 5 } & Türkiye & Meksika & Endonezya & Nijerya \\
\hline $\mathbf{2 0 0 6}$ & $-0,7017$ & 0,4550 & 0,1842 & 0,9776 \\
\hline $\mathbf{2 0 0 7}$ & $-0,6454$ & 0,3742 & 0,1409 & 0,9775 \\
\hline $\mathbf{2 0 0 8}$ & $-0,3351$ & 0,2644 & 0,1296 & 0,9882 \\
\hline $\mathbf{2 0 0 9}$ & $-0,4950$ & 0,3194 & 0,2668 & 0,9853 \\
\hline $\mathbf{2 0 1 0}$ & $-0,5487$ & 0,2615 & 0,2593 & 0,9847 \\
\hline $\mathbf{2 0 1 1}$ & $-0,5093$ & 0,2281 & 0,2560 & 0,8930 \\
\hline $\mathbf{2 0 1 2}$ & $-0,4682$ & 0,2203 & 0,1945 & 0,9860 \\
\hline $\mathbf{2 0 1 3}$ & $-0,5152$ & 0,1935 & 0,1155 & 0,7965 \\
\hline $\mathbf{2 0 1 4}$ & $-0,5475$ & 0,1117 & 0,0757 & 0,8499 \\
\hline $\mathbf{2 0 1 5}$ & $-0,5406$ & $-0,0805$ & 0,1612 & 0,6814 \\
\hline $\mathbf{2 0 1 6}$ & $-0,5946$ & $-0,1611$ & 0,1832 & 0,5185 \\
\hline $\mathbf{2 0 1 7}$ & $-0,6054$ & $-0,2221$ & 0,1835 & 0,6605 \\
\hline $\mathbf{2 0 0 6 - 2 0 1 7}$ & $\mathbf{- 0 , 5 4 2 2}$ & $\mathbf{0 , 1 6 3 7}$ & $\mathbf{0 , 1 7 9 2}$ & $\mathbf{0 , 8 5 8 3}$ \\
Ortalama & & & & \\
\hline
\end{tabular}

Kaynak: Yazar tarafindan hesaplanmıştır.

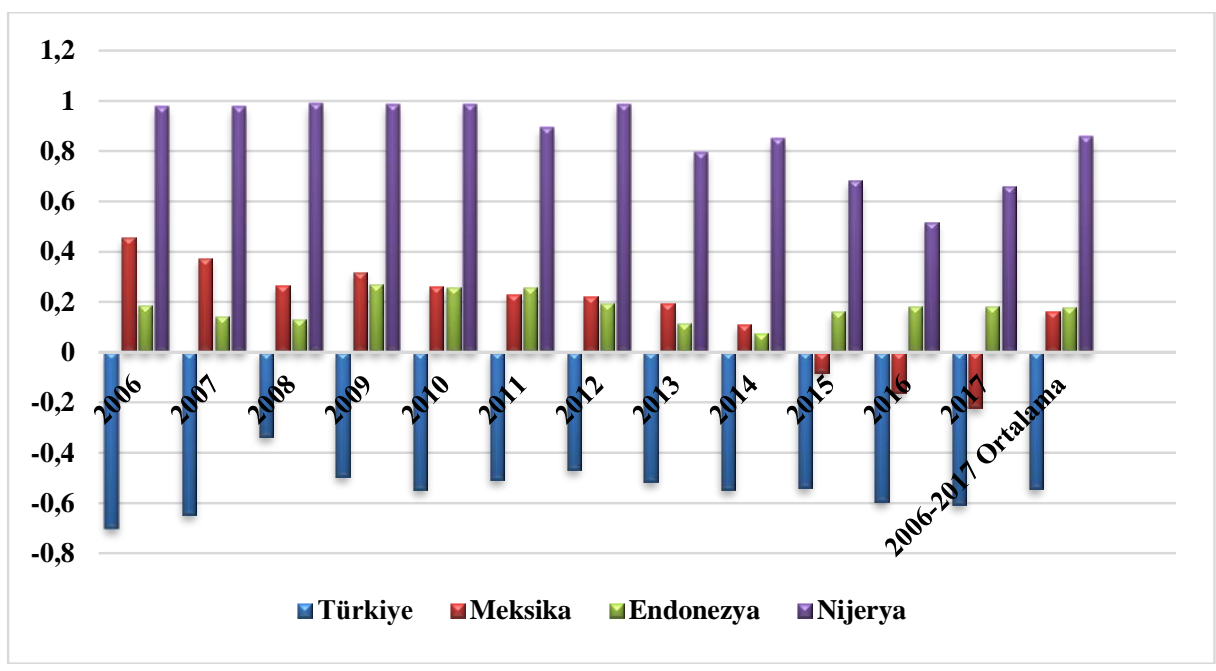

Şekil 5. MINT Ülkeleri Enerji Sektörü TBI İndeks Değerleri Grafiği Kaynak: Yazar tarafindan oluşturulmuştur. 


\section{Sonuç}

$\mathrm{Bu}$ çalışmada üretim için gerekli ve en önemli girdi kaynağı olan enerji sektörünün rekabet gücü MINT ülkeleri için TBI indeksi ile ölçülmüştür. Rekabet gücü SITC Rev.3 sınıflamasına göre 2000-2017 dönemi için iki dijitli enerji sektörü alt sektörleri itibariye, 2006-2017 dönemi için de enerji sektörünün genelini oluşturan tek dijitli veriler ile tespit edilmiştir.

2000-2017 dönemine ait analiz sonuçlarına göre, Türkiye ekonomisi 32, 33 ve 34 kodlu sektörlerde net ithalatçı konumdadır. 35 kodlu sektörde ise sadece 2004-2011 döneminde net ihracatçı konumdadır. Meksika ekonomisinin enerji sektörünün rekabet gücü ise Türkiye ile benzer ancak daha iyi durumdadır. Meksika 2000-2017 döneminde 32 ve 34 kodlu sektörlerde net ithalatçı konumdadır. 33 kodlu sektörde 2000-2015 döneminde net ihracatç1, 35 kodlu sektörde ise 2002-2016 döneminde net ihracatç1 konumdadır. Endonezya 2000-2017 döneminde 32 ve 34 kodlu sektörde, Nijerya aynı dönemde 33 ve 34 kodlu sektörde net ihracatçı konumdadır.

2006-2017 dönemine ait analiz sonuçlarına göre, Türkiye yıllar itibariyle enerji sektöründe net ithalatçı konumdadır. Meksika 2006-2014 döneminde net ithalatçı konumdayken, enerji sektöründeki rekabet üstünlüğünü 2015 yılından itibaren kaybetmiştir. Endonezya ve Nijerya ise yıllar itibariyle net ihracatçı konumdadır. 20062017 döneminde enerji sektörü rekabet gücü sıralaması Nijerya, Endonezya, Meksika ve Türkiye şeklindedir. Enerji sektörü rekabet gücü açısından en zayıf ülke Türkiye'dir. Dolayısıyla Türkiye ekonomisi açısından enerji sektöründe rekabet gücünü artıracak etkin enerji politikası uygulamaları kaçınılmazdır.

Öncelikle Türkiye'nin, bazı demografik avantajları nedeniyle önümüzdeki 20 yıl için geleceğin ekonomileri olarak adlandırılan MINT ülkeleri arasındaki konumunu koruyabilmesi, özellikle enerji sektöründe rekabet gücünü artırabilecek politikaları zorunlu kılmaktadır. Türkiye ve diğer Gelişmekte Olan Ülkeler'de cari açıkların en önemli nedeni enerji ithalatıdır. Enerji ithalatını azaltacak ve enerji üretimini artıracak etkin politikalar ve sektöre yapılacak yatırımlar, ülkelerin sürdürülebilir ekonomik büyümesi açısından da önem arz etmektedir. Ancak bu şekilde sektördeki rekabet gücü tesis edilebilir ve artırabilir.

Türkiye ekonomisi hızla büyümeye devam eden ve enerji tüketimi de buna bağlı olarak hızla artan bir ülkedir. Türkiye'nin özellikle de birincil enerji kaynaklarında dışa bağımlılı̆̆1 yüksektir. Bu nedenle de yüksek miktarda dış ticaret açığı ve cari işlemler açığı vermektedir. Küresel enerji fiyatlarındaki gelişmeler, ülkenin enerji fiyatlarını ve buna bağlı olarak da dış finansman ihtiyacını doğrudan etkilemektedir. Türkiye enerji politikalarının gündeminde güçlü ve güvenilir bir enerji alt yapısının oluşturulması, enerji sektöründe dışa bağımlılığın azaltılması ve optimum kaynak çeşitliliğini sağlamak için tüm alternatif enerji kaynaklarının değerlendirilmesi yer almaktadır.

Türkiye'nin uyguladığı enerji politikalarında, yenilenebilir enerji kaynaklarına yapılan yatırımların artırılması ve enerjide yerli kaynakların teşvik edilmesi yönünde düzenlemeler yer almaktadır. Hükümet tarafından yenilenebilir enerji kaynaklarından ve yerli kaynaklardan elektrik üreten santrallere verilen teşvikler artış göstermektedir. Bununla birlikte, Türkiye'deki mevcut enerji üretimi, toplam talebi karşılayamamakta ve ülkenin enerji ithalatı yapma zorunluluğu devam etmektedir. 
Yenilenebilir enerji kaynaklarının, fosil yakıtlarla karşılaştırıldığında yurtiçi kaynaklara dayalı olması, kendini yenileyebilmesi, çevreye zarar vermemesi gibi avantajları vardır. Bu bağlamda bu enerji kaynaklarına yapılan ve yapılması gereken yatırımlara hükümet tarafından verilen teşviklerin artırılması gerekmektedir. Böylece enerji sektöründe dışa bağımlı olan Gelişmekte Olan Ülkeler'in enerji ithalatı ve dolaysıyla cari açıkları azalacak ve ülkelerin rekabet gücü artacaktır.

\section{Kaynaklar}

Altay, B. ve Gürpınar, K. (2008). Açıklanmış Karşılaştırmalı Üstünlükler ve Bazı Rekabet Gücü Endeksleri: Türk Mobilya Sektörü Üzerine Bir Uygulama. Afyon Kocatepe Üniversitesi, I.I.B.F. Dergisi, X(I), 257-274.

Altay Topcu, B. ve Sümerli Sarıül, S. (2015). Comparative Advantage and The Products Mapping of Exporting Sectors in Turkey. Akademik Sosyal Araştırmalar Dergisi, 3(18), 330-348.

Arastou, K. (2008). Kazakhstan's Revealed Comparative Advantage vis-à-vis the EU-27. ECIPE Working Paper, No.03, 1-13.

Ardıç, B. (2017). Türkiye'nin Açıklanmış Karşılaştırmalı Üstünlüklerinin Belirlenmesi. ECONDER International Academic Journal, 1(1), 8-21.

Balassa, B. (1965). Trade Liberalisation and Revealed Comparative Advantage. The Manchester School, 33(2), 99-123.

Çakmak, A. (2005). Açıklanmış Karşılaştırmalı Üstünlükler ve Rekabet Gücü: Türkiye Tekstil ve Hazır Giyim Endüstrisi Üzerine Bir Uygulama. Ege Akademik Baklş, 5(1), 65-76.

Dalum, B., Laursen, K. ve Villumsen, G. (1998). Structural Change in OECD Export Specialization Patterns: De-specialization and Stickiness. International Review of Applied Economics, 12 (3), 423-443.

Erdoğan, S. ve Gürbüz, S. (2014). Türkiye'de Enerji Tüketimi ve Ekonomik Büyüme İlişkisi: Yapısal Kırılmalı Zaman Serisi Analizi. Selçuk Üniversitesi Sosyal Bilimler Enstitüsü Dergisi, 32, 79-87.

Ergün, S. (2005). Türkiye Enerji (Elektrik, Gaz, Su) Sektöründe Verimlilik Göstergeleri. TMMOB Türkiye V. Enerji Sempozyumu, 21-23 Aralık, Ankara.

Erkan, B. ve Batbaylı, Ş. (2017). Karadeniz Ekonomik İşbirliği Örgütü (KEİ) Üyesi Ülkelerin Küresel Pazarlardaki Karşılaştırmalı Üstünlükleri. Marmara Üniversitesi Siyasal Bilimler Dergisi, 5 (Özel Sayı), 31-49.

Hayaloğlu, P. (2015). MINT Ülkelerinde Demokrasi Ekonomik Büyümeyi Nasıl Etkilemektedir?. Uluslararası Ekonomi ve Yenilik Dergisi, 1(1), 17-29.

Kuşat, N. (2018). Açıklanmış Karşılaştırmalı Üstünlükler İndeksi Çerçevesinde AB Aday Ülkeleri Enerji Sektörü Rekabet Gücü Analizi (2006-2016). Uluslararası Bilimsel Araştırmalar Dergisi (IBAD), 3(1), 362-376.

Lafay, G. (1992). The Measurement of Revealed Comparative Advantages. In: Dagenais, M.G. \& Muet, P.A. (eds.), International Trade Modelling. London: Chapman \& Hall.

Rossato, F.G.F.S., Susaeta, A., Adams, D.C., Hidalgo, I.G, Araujo, T.D. ve Queiroz, A. (2018). Comparison of Revealed Comparative Advantage İndexes With Application to Trade Tendencies of Cellulose Production From Planted Forests in 
Ç.Ü. Sosyal Bilimler Enstitüsü Dergisi, Cilt 28, Sayı 2, 2019, Sayfa 272-285

Brazil, Canada, China, Sweden, Finland and The United States. Forest Policy and Economics, 97, 59-66.

Startiene, G. ve Remeikiene, R. (2014). Evaluation of Revealed Comparative Advantage of Lithuanian Industry in Global Markets. Procedia-Social and Behavioral Sciences, 110, 428-438.

UN Comtrade, International Trade Statistics Database, https://comtrade.un.org/db/dqQuickQuery.aspx, Erişim Tarihi: 05.01.2019.

Vollrath, T.L. (1991). A Theoretical Evaluation of Alternative Trade Intensity Measures of Revealed Comparative Advantage. Weltwirtschaftliches Archiv, 127(2), 265280.

Widodo, T. (2016). Comparative Advantage of Energy Products in the Midst of ASEAN Economic Integration. MPRA, Paper No. 79964, 1-17. 